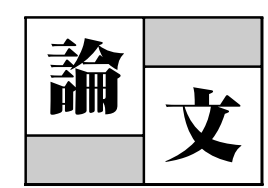

\title{
大曲率半径の面を有するプラスチック成形品のそり数值解析
}

\author{
舘 山 弘 文 $^{* 1} \cdot$ 土屋 淳 志*1 $^{*}$ 小 山 清 人 $^{* 2}$
}

\section{The Warpage Analysis of Plastic Parts with Large Radii of Curvature}

\begin{abstract}
Tateyama, Hirofumi*1/Tsuchiya, Atsushi*1/Koyama, Kiyohito*2
In general, warpage of injection molded parts is greatly affected by part design and molding conditions. Since the mechanisms of warpage are complicated, the ability to predict and avoid warpage is very difficult and has not yet been established. When parts are designed in $3-\mathrm{D}$, it is especially difficult to predict and take effective counter measures against warpage.

In this study, numerical warpage analysis and molding tests of plastic parts with large radii of curvature were carried out. Warpage for several patterns of molding parameters were compared for analysis and actual molding tests. Our results show that the amount of warpage predictd by the analysis was larger than that in the actual molding for all molding parameters tested. The differences between analytical and actual warpages correlated with initial warpage, which occurred just after the molded part was taken out from the tool.
\end{abstract}

Key words : Injection molding/Warpage numerical analysis/Shrinkage/Precision of analysis

\section{1. 緒言}

熱可塑性プラチックの射出成形では, 溶融樹脂を低温に 保持された金型に充填し，冷却固化を経て成形品が得られ る.この冷却固化の過程において，金型内に充填された樹 脂は，収縮を伴いながら成形品形状を形作るが，その成形 条件, 成形品形状等の影響を受け, 成形品全体が均一に収 縮することはない，結果として，成形品にそり変形等の成 形不良が発生する。

近年，数值解析を用いて成形品のそりを事前に予測する 手法が提案されている. しかし, 成形品そりの発生メカニ ズムは非常に複雑で, 予測精度は未だ十分とは言えない。

一般に, これまでの数值解析によるそり予測は, 平板等 の単純形状に扔いては, 実用性が認められている(1) 2)。し かし，リブやボス等がある形状や箱型のような立体的な形 状になると, その予測精度は著しく低下する。このため, 基礎的な研究も進められている

*1 福島市蓬莱町 1-11-1（†960-8506）

ムネカタ株R\&D センター

Research \&Development center, Munekata Co., Ltd.,

1-11-1, Hourai-cho, Fukushima, 960-8506, Japan

*2 山形大学工学部機能高分子工学科

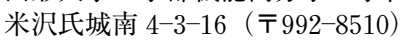

Department of Polymer Science and Engineering,

Faculty of Engineering, Yamagata University

4-3-16, Jounan, Yonezawa 992-8510, Japan

2003.6. 2 受理
そこで著者らは, 前報りにおいて, そり挙動が観察しや すい大きな曲率半径の面を有する成形品を用い, 成形品に 経時的に発生するそりの詳細観察結果を報告した。すなわ ち成形品の最終そりは, 成形品が金型から取り出された瞬 間に発生する初期そり，および金型から取り出されてから 収縮が安定するまでに発生するその後のそりが合成された ものであることを示した．また初期そりおよび最終そりの 成形条件依存性に関しても報告した。

本報においては, 前報と同形状について有限要素法を用 いた数值解析により, そりの解析を行い実成形デー夕と詳 細比較し考察した。

\section{2. 実験}

本研究では, 成形実験とコンピューターを用いた数值解 析を実施した。以下に詳細を示した。

\section{1 成形品形状と使用樹脂}

本研究で用いた成形品形状を図 1 に示した。本モデルは, 家電製品のコントロールパネルあるいはその扉をイメージ し, 大きな曲率半径 $\mathrm{R}_{0}=3260 \mathrm{~mm}$ を持った曲面部と外周 に垂直方向のリブが設置された形状である.ゲートは, 機 能性, 外観品質要求の点からサイドゲート 1 点とし, 成形 品中央下部に設置した，樹脂は，このような製品でよく用 いられる耐衝撃ポリスチレンを使用した。

\section{2 実験条件の設定}

実験条件の詳細を表 1 に示した。本実験では，そりに与 える成形条件の影響を調查するため, 樹脂温度, 充填時間, 


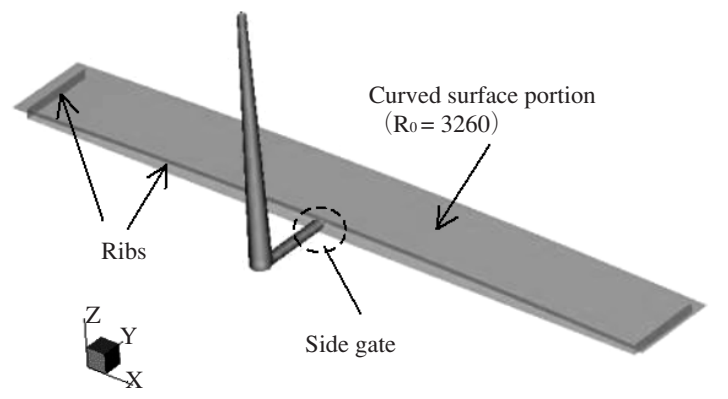

$\mathrm{L} \times \mathrm{W} \times \mathrm{H}=275 \times 35 \times 8$ Wall thickness : 3.3 Rib thickness : 1.5

(Unit : mm)

Fig. 1 Illustration of part model

Table 1 Conditions of experiment for warpage analysis and molding

\begin{tabular}{c|l|l}
\hline Molding Machine & $\begin{array}{l}\text { Clamping force of machine is 80 tf } \\
(794 \mathrm{kN})\end{array}$ \\
\hline \multirow{2}{*}{ Resin } & $\begin{array}{l}\text { High Impact Polystyrene ; MS 500 } \\
(\text { MFR : } 5.0 \mathrm{~g} / 10 \mathrm{~min}), \quad \text { Idemitsu } \\
\text { Petrochemical Co., Ltd. }\end{array}$ \\
\hline Material temperature $\left({ }^{\circ} \mathrm{C}\right)$ & \multicolumn{2}{|c}{$205 \sim 237$} \\
\hline Filling time $(\mathrm{s})$ & $1.3 \sim 5.0$ \\
\hline Holding pressure $(\mathrm{MPa})$ & \multicolumn{2}{|c}{$48.9 \sim 81.5$} \\
\hline Holding time $(\mathrm{s})$ & $5 \sim 10$ \\
\hline Cooling time $(\mathrm{s})$ & \multicolumn{2}{|c}{$10 \sim 30$} \\
\hline \multirow{2}{*}{ Tool temperature $\left({ }^{\circ} \mathrm{C}\right)$} & Fixed side of the tool & 30 \\
\cline { 2 - 3 } & Movable side of the tool & 12 \\
\hline
\end{tabular}

保持圧力，保圧時間，冷却時間を変動要因とした。ただし， ヒケ，バリあるいはオーバーパックやバックフロー等の成 形不良のない範囲で成形条件を選定し，最終的に表 2 に示 した条件を設定した。

また金型温度は，成形品に複雑な熱挙動を与え，そりを 発生させる要因として知られている ${ }^{9)}$ - 11) 離型時に成形品 の固定側と可動側の温度差が大きいと，他の成形条件の依 存性の結果に影響を示す場合がある。そのため本実験では， 取り出し時の成形品表面温度およびその後の冷却速度がほ
ぼ均一になるように，固定側および可動側金型の温度と冷 却水量を事前に調整し，その金型温度条件を固定した。

\section{3 数値解析}

数值解析用ソフトに Moldflow Plastics Insight 3.1 (Moldflow 社) を用いた. 図 1 に示したモデル形状で，最 初に充填・保圧解析および金型冷却解析を行った。次に, 算出された金型のキャビティ面温度分布を境界条件とした 充填・保圧解析を行った。さらに圧力，温度等を考慮した 成形品の体積収縮率分布を算出した。そり解析では，この 体積収縮率分布からの応力を用いて, 成形品の変形量を算 出した。一般的に，そり解析では経時的なシミュレーショ ンが行えないため，最終的な成形品のそり量のみ算出した. 解析条件は，上記に示した実成形条件と全く同じ条件と した。

\section{4 そり解析における拘束点の設定}

そり量を算出する際に，成形品の一部を固定する拘束点 の設定が必要となる．図 2 に示したように，通常よく用い られる成形品曲面部端面を拘束点に設定する方法 (Case 1) と，後述のそりの定義から結果を比較しやすい成形品曲面 部中央を拘束点に設定する方法（Case 2）の二つを事前に 検討した。その結果，どちらの設定方法でも，成形品の最 終そり量は全く同じであった。よって本実験においては, Case 2 の設定方法を採用した.

\section{5 成形品のそり評価方法とそり変化量の定義}

図 3 に示したように，金型の実測值である曲率半径 $\mathrm{R}_{0}$ $=3260 \mathrm{~mm}$ での Z 軸方向の変位を基準とし, $0 \mathrm{~mm}$ とした. 金型から成形品を取り出した直後からそりが安定するま で継続的にその変位を計測した．前報で報告したとおり， 本実験で用いた大曲率半径の面を有する成形品では，金型 から取り出してから，経時的に二つの異なったそり変形が 発生する. そのため, 成形実験において成形品を金型から 取り出した瞬間に発生したそりを $\alpha$ とし，これを初期そ りと定義した。 さらにその後室温で徐々に冷却され，樹脂 収縮が安定した時点でのそりを $\beta$ とし，これを最終そり と定義した.

また $\beta-\alpha$ は，図 4 に示したように， $\beta$ と $\alpha$ の值から 算出し，成形品を取り出し後から経時的に発生した総変位

Table 2 Results of warpage measurement

\begin{tabular}{l|c|c|c|c|c}
\cline { 3 - 5 } \multicolumn{2}{c|}{} & \multicolumn{3}{c|}{ Actual molding } & Analysis \\
\hline \multirow{2}{*}{ Molding parameter } & condition & $\begin{array}{c}\text { Initial warpage } \\
\alpha(\mathrm{mm})\end{array}$ & $\begin{array}{c}\text { Final warpage } \\
\beta(\mathrm{mm})\end{array}$ & $\begin{array}{c}\text { Total deformation } \\
\beta-\alpha(\mathrm{mm})\end{array}$ & $\begin{array}{c}\text { Final warpage } \\
\beta \mathrm{s}(\mathrm{mm})\end{array}$ \\
\hline \multirow{2}{*}{$\begin{array}{l}\text { Material } \\
\text { temperature }\left({ }^{\circ} \mathrm{C}\right)\end{array}$} & 205 & -1.719 & 0.424 & 2.143 & 3.387 \\
\cline { 2 - 6 } & 237 & -1.470 & 1.735 & 3.205 & 4.215 \\
\hline \multirow{2}{*}{ Filling time $(\mathrm{s})$} & 1.3 & -1.719 & 0.424 & 2.143 & 3.387 \\
\cline { 2 - 6 } & 5.0 & -1.676 & 0.21 & 1.886 & 2.113 \\
\hline $\begin{array}{l}\text { Holding pressure } \\
(\mathrm{MPa})\end{array}$ & 48.9 & -1.719 & 0.772 & 2.491 & 2.193 \\
\cline { 2 - 6 } & 81.5 & -0.216 & 2.261 & 2.477 & 4.337 \\
\hline \multirow{2}{*}{ Holding time $(\mathrm{s})$} & 5 & -0.68 & 1.277 & 1.957 & 1.691 \\
\hline \multirow{2}{*}{\begin{tabular}{c} 
Cooling time $(\mathrm{s})$ \\
\cline { 2 - 6 }
\end{tabular}} & 10 & -0.377 & 1.128 & 1.505 & 2.156 \\
\cline { 2 - 6 } & 10 & -0.822 & 1.362 & 2.184 & 1.79 \\
\hline
\end{tabular}




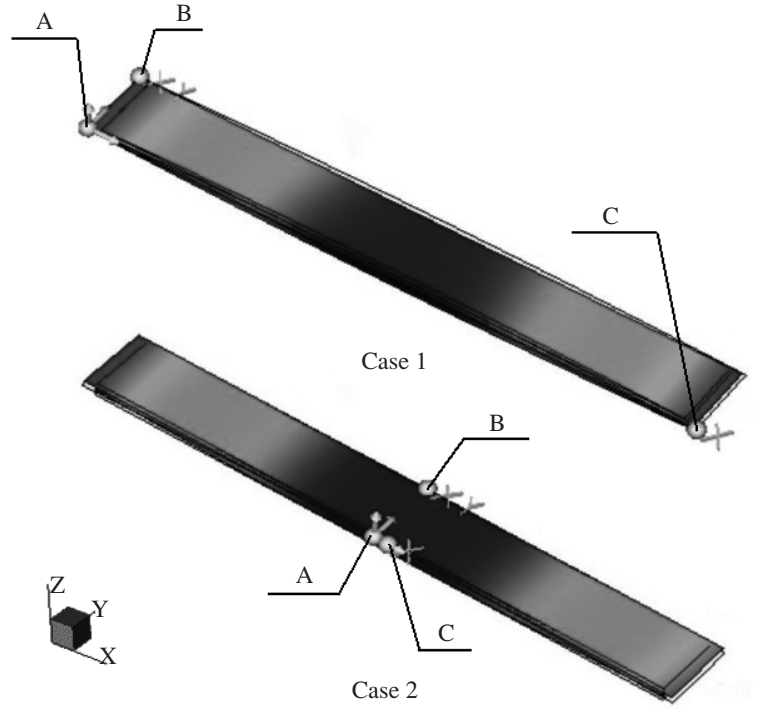

Point A: Displacements of X, Y and Z directions are stationary Point B: Displacements of X and Y directions are stationary Point C: Displacement of $\mathrm{X}$ direction is stationary

Fig. 2 Setting of restriction points in warpage analysis

Radius of curvature of the tool

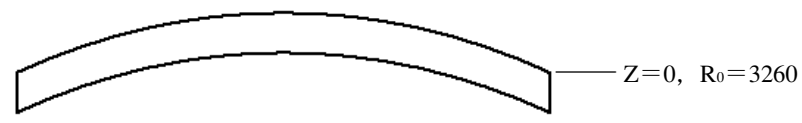

Initial warpage

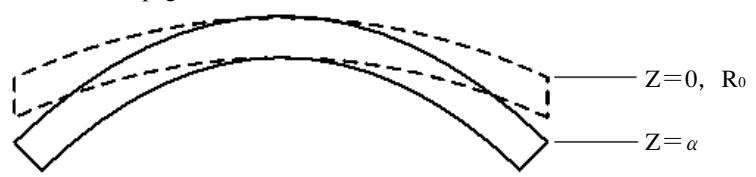

Final warpage

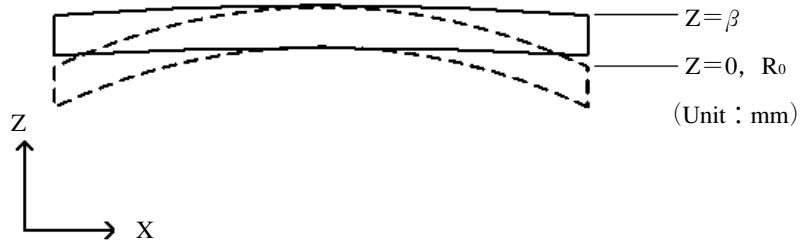

$\mathrm{R}_{0}:$ Radius of curvature of the tool

$\mathrm{Z}$ : Displacement in the $\mathrm{Z}$ direction

$\alpha$ : Initial displacement by warpage

$\beta$ : Final displacement by warpage

Fig. 3 Definition of initial warpage and final warpage

量とした。

一方, 数值そり解析で算出した成形品の最終そりを $\beta \mathrm{s}$ と定義した。

\section{3. 結果および考察}

\section{1 実成形と数值解析におけるそりの結果}

表 1 で示した条件に基づき, 実成形の初期そり $\alpha$, 最 終成形品そり $\beta$, さらに総変位量 $\beta-\alpha$ の結果と数值解

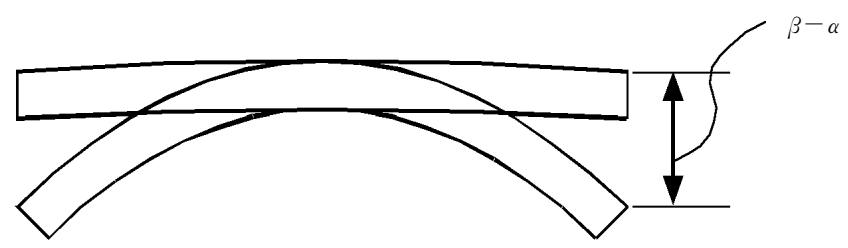

$\beta-\alpha$ : Total deformation; amount of initial warpage and final warpage

Fig. 4 Definition of total deformation

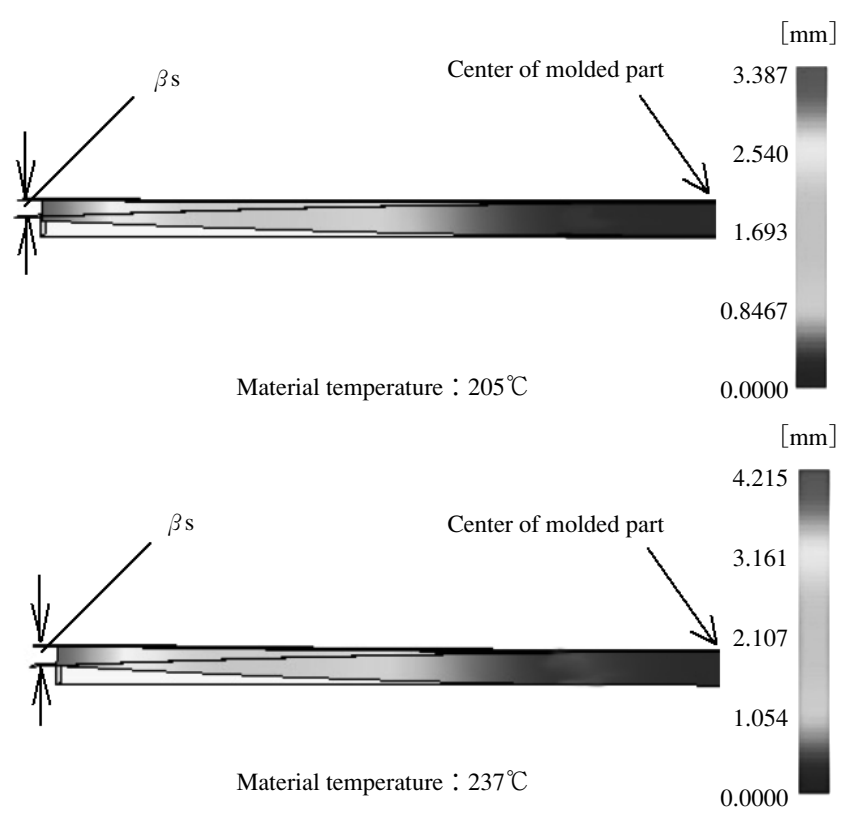

Fig. 5 Displacements of deformed parts in warpage analysis

析で求めたそり量 $\beta \mathrm{s}$ の結果を表 2 によめて示した.こ こで樹脂温度を例にして説明すると, 樹脂温度が $205^{\circ} \mathrm{C}$ の 場合, 実成形での初期そり $\alpha$ は $-1.719 \mathrm{~mm}$, 最終成形品 そり $\beta$ は $0.424 \mathrm{~mm}$, 総変位量 $\beta-\alpha$ は $2.143 \mathrm{~mm}$ になっ た. $237^{\circ} \mathrm{C}$ の場 合, $\alpha$ は $-1.470 \mathrm{~mm}, \beta$ は $1.735 \mathrm{~mm}, \beta$ - $\alpha$ は $3.205 \mathrm{~mm}$ であった. 同樹脂温度条件のそり解析

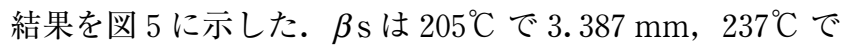
$4.215 \mathrm{~mm}$ を示した。

同様にして，それぞれの実験条件における，そり量を実 成形および数值解析で求めた.

\section{2 実成形と数值解析の比較}

実成形と数值解析を比較検討するため, 図 6 に実成形に おける最終そり $\beta$ と数值解析のそり $\beta \mathrm{s}$ の関係を示した. また $\beta \mathrm{s}=\beta$ の直線をグラフに示した。 このグラフにおい て, 実成形の最終そり $\beta$ と数值解析のそり $\beta \mathrm{s}$ が全く同 じ值を示せば， $\beta \mathrm{s}=\beta$ の直線上にプロットされる．また， $\beta$ と $\beta \mathrm{s}$ の条件依存性が同じであれば, その直線の傾きは プラスを示す. 図 6 において, 樹脂温度, 充填時間, 保持 圧力, 冷却時間は, 直線の傾きがプラスとなり, すなわち 実成形の最終そり $\beta$ と数值解析のそり $\beta \mathrm{s}$ は同様な条件 依存性を示した。一方, 保持時間は, 直線の傾きがマイナ スとなり， $\beta$ と $\beta \mathrm{s}$ は異なる条件依存性を示した。ただし 他の条件と比較し, 条件の変化により, データの移動量が 小さく, かつ $\beta \mathrm{s}=\beta$ の直線に近いことから, 保持時間に 


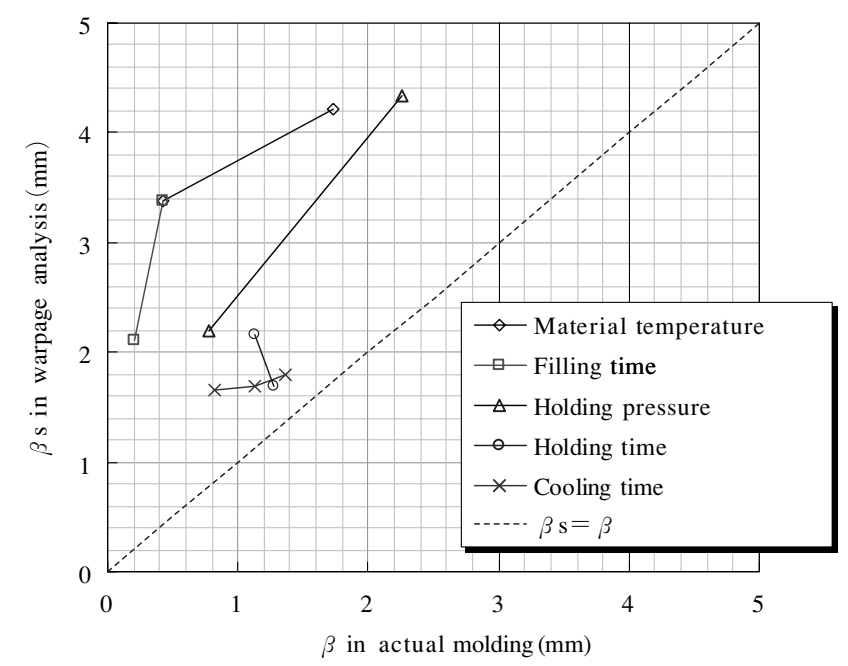

Fig. 6 Relationship between $\beta \mathrm{s}$ in warpage analysis and $\beta$ in actual molding

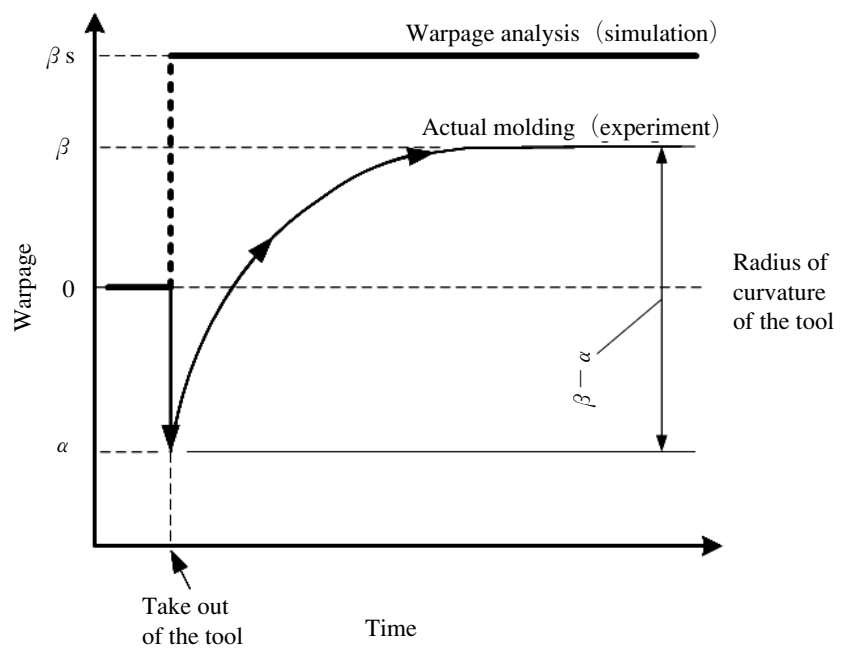

Fig. 7 Illustration of warpage behavior

関して, $\beta \mathrm{s}$ と $\beta$ は近い值を示していると考える.

このように実成形でのそり挙動の条件依存性は，数值解 析でおおよそ再現できた。

ただし，図 6 において $\beta \mathrm{s}>\beta$ の領域に，すべてのプロッ トが存在した。すなわちすべての条件において，数值解析 のそり $\beta \mathrm{s}$ は, 実成形における最終そり $\beta$ よりも大きな 值を示した。

\section{3 実成形と数値解析結果の差について}

数值解析によるそり量が, 実際の成形のそり量より大き くなったことについて図 7 で考察した。実際の成形におい ては，成形品を金型から取り出した瞬間に，金型曲率半径 よりも小さくなる初期そり $\alpha$ が発生する。ささらにそこを 基点として, 成形品の収縮が安定するまで, そり変形が継 続し最終そり $\beta$ が決定される.

ここで初期そりは，すべてマイナス方向に生じることか ら, 成形品の製品表面側（型固定側面）よりも製品裏面側 （型可動側面）の方が，瞬間的に大きな変形が起こったと 考えられる.すなわち, 製品裏面側に大きな残留応力が発 生しており，それが瞬間的に開放したと推察する.

数值解析においては, 成形品を金型から取り出すまでの

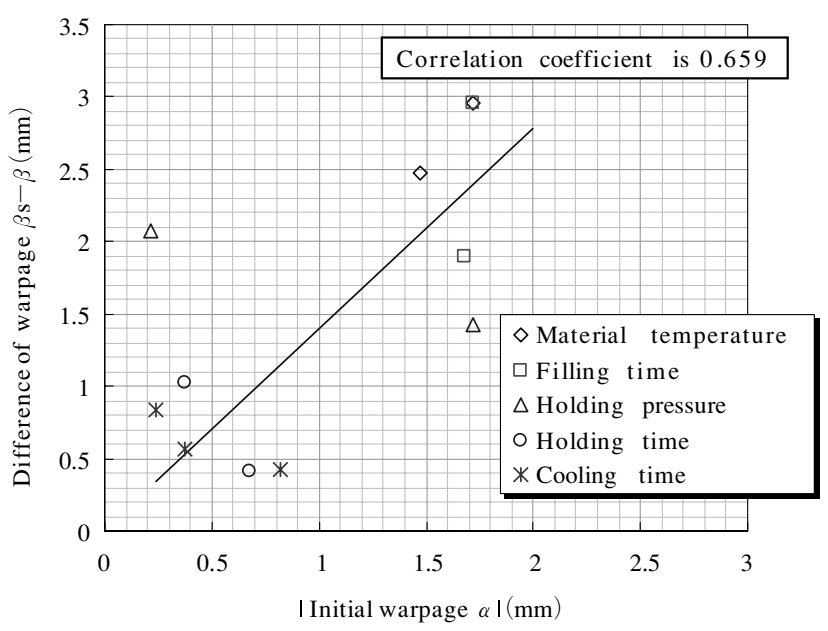

Fig. 8 Relationship between $\beta$ s $-\beta$ and $|\alpha|$

間，金型内で成形品全体は不均一な収縮分布になっている が，型固定側と型可動側の接触部の樹脂は，金型表面に完 全に固定されていると仮定している，従って，実成形のよ うな製品表面側と裏面側に大きな応力の差が発生すること はなく，初期そりは表現されない。このように数值解析で は，金型形状を基点として，そこから成形品のそりが求め られ，最終そり $\beta \mathrm{s}$ が決定される。

以上のように数值解析においては，実成形で見られる初 期そり $\alpha$ の現象が考慮されず, 数值解析のそり $\beta \mathrm{s}$ は実 成形でのそり $\beta$ よりも高い值を示したと考えられる.こ の原因とメカニズムについて今後明確にすることが，そり 予測の大きな課題であると考える.

\section{4 最終そり量の差異と初期そりとの関係}

上記に示した $\beta \mathrm{s}$ と $\beta$ との差異と初期そり $\alpha$ との関係 を明確にするため, 図 8 のように縦軸に, 数值解析の最終 そり $\beta \mathrm{s}$ と実成形の最終そり $\beta$ の差 $\beta \mathrm{s}-\beta$ を，横軸に， 実成形での初期そりの大きさ $|\alpha|$ (絶対值) を, 各々の 成形条件についてプロットした。

その結果， $|\alpha|$ の増加により, $\beta \mathrm{s}-\beta$ は増加する傾向 にあった.ここで，ピアソンの相関係数を算出したところ， 0.659 であり，正の相関が見られた.

よって全体的な傾向としては，実成形における $\alpha$ の絶 対值が大きくなると, 数值解析の最終そり $\beta \mathrm{s}$ はその分大 きく算出され, 予測精度が低くなる.

\section{4. 結言}

本報では，そり挙動が観察しやすい大きな曲率半径の面 を有する成形品形状を用いて, 実際の成形実験と有限要素 法を用いた数值解析を行い, 成形品の最終そり量を比較し, 詳細考察した。

その結果，以下のことを明らかにした。

(1)実成形と数值解析を比較した場合，成形品の最終そり量

は，数值解析の方が大きい傾向にある.

(2)数值解析で算出した最終そり量と実成形での最終そり量 の差は，実際の成形で見られる初期そりの量に相関が ある。 
参 考 文 献

1 ）大塚弘已，望月智仁，大須賀晴信：成形加工，13（2）, 102 (2001)

2 ）山部 昌, 大塚弘已, 亀田隆夫, 瀬戸雅宏, 道井貴幸 : 成形加工，14（11），690（2002）

3 ) 松岡信一, 藤木武志：塑性加工連合講演会講演論文 集，51 st，463（2000）

4) MCILVAINE, J. : Des. 21 ST Century, 89 (1996)

5 ) 四ツ柳真彦, 及川 功, 青葉たかし, 吉田豊満, 福本 宏昭：合成樹脂，29（11），25（1983）

6 ）浜田尊明, 是沢宏之, 楢原弘之, 鈴木 裕：精密工学
会九州支部地方講演会講演論文集 1997，27（1997）

7 ) LEE B. H. and KIM B. H : Soc. Plast. Eng. Annu. Tech. Conf., $54^{\text {th }}(1), 692$ (1996)

8 ) 舘山弘文, 土屋淳志, 小山清人 : 成形加工, 15 (10), 694 (2003)

9 ）プラスチック成形加工学会編：成形加工における移動 現象，34 (1997)，シグマ出版

10）プラスチック成形加工学会編 : 先端成形加工技術, 81 (1999)，シグマ出版

11）射出成形辞典編集委員会編：射出成形辞典, 316 (2002), 平河工業社 